\title{
EL COLONIALISMO HUMANITARIO: PRESERVACIÓN DEL SUJETO BIOLÓGICO O ANIQUILACIÓN DEL SUJETO CULTURAL?
}

\author{
O COLONIALISMO HUMANITÁRIO: PRESERVAÇÃO DO \\ SUJEITO BIOLÓGICO OU ANIQUILAÇÃO DO SUJEITO \\ CULTURAL?
}

Jesús José Diez Canseco Carranza ${ }^{1}$

\section{RESUMEN}

En la Amazonía, la situación del indígena es un problema que dura más de 500 años y aún no se resuelve. En este contexto, el sujeto en cuestión es visto desde distintas perspectivas y, simultáneamente, como blanco de todo tipo de violencias. Una de las más perjudiciales es su confinamiento a los márgenes de los espacios nacionales. Del mismo modo, las presiones ejercidas desde "el centro" con el fin de eliminar sus soportes culturales y sobreviva, así, en el seno de un Estado-nación que pone en duda sus capacidades cognitivo-intelectivas y hasta su propia humanidad. Ante esta situación de expoliación y apagamiento surge, a lo largo del tiempo, un discurso proteccionista que abogó por la preservación física del indígena amazónico. Sin embargo, para que esto ocurra el individuo asediado debió capitular (muchas veces) y convertirse en un nuevo sujeto. En un sujeto artificial, sin identidad y "sin alma". Ejemplos de lo dicho aparecen en textos como The devil's paradise de Walter Hardenburg, The blue book de Roger Casement y El sueño del celta de Mario Vargas Llosa; narrativas que, a través de la metodología del análisis del discurso, serán abordadas y problematizadas a lo largo del presente trabajo.

\section{PALABRAS CLAVE}

Amazonía. Culturas indígenas. Colonialidad. Humanitarismo.

\section{RESUMO}

$\mathrm{Na}$ Amazônia, a situação do indígena é um problema que dura mais de 500

1 Mestre em Letras: Linguagem e Identidade pela Universidade Federal do Acre (2018) e Professor da Universidade César Vallejo, com sede em Trujillo, Peru. 
anos e ainda não foi resolvida. Neste contexto, o sujeito em questão é olhado a partir de diferentes perspectivas e, simultaneamente, como alvo de todo tipo de violências. Uma das mais prejudiciais é o seu confinamento nas margens dos espaços nacionais. Do mesmo modo, as pressões exercidas desde "o centro" com o propósito de eliminar seus apoios culturais e assim sobreviver dentro de um Estado-nação que questiona suas capacidades cognitivas-intelectuais e até sua própria humanidade. Devido à situação de exploração e extinção surge, ao longo do tempo, um discurso protecionista que defendeu a preservação física do índio amazônico. No entanto, para que isso aconteça, o indivíduo assediado deve ter capitulado e tornar-se um novo sujeito. Em um sujeito artificial, sem identidade e "sem alma". Exemplos do dito aparecem em textos como The devil's paradise de Walter Hardenburg, The blue book de Roger Casement e El sueño del celta de Mario Vargas Llosa; narrativas que, através da metodologia do analise do discurso, serão abordadas e problematizadas no percurso do presente trabalho.

\section{PALAVRAS CHAVE}

Amazônia. Culturas indígenas. Colonialidade. Humanitarismo.

Dentro de los procesos de creación y ocupación del espacio, se exigió en los territorios conquistados, la implantación de las mismas reglas jurídicas que organizaban a las metrópolis. A partir de estos registros, los lugares se fueron redefiniendo con el objetivo de facilitar la valoración económica y el movimiento mercantil en las tierras expropiadas. En este nuevo contexto, era posible dejar al colonizado controlar sus propias representaciones geográficas y jurídicas? Improbable. Muy por el contrario, debía homogeneizarlo jurídicamente y someterlo a las normas y valores de la metrópolis. ¿Qué otra cosa se hizo en América Latina y, especialmente, en la Amazonía desde el siglo XVI hasta nuestros días? La respuesta de los portadores de la civilización occidental fue inmediata. Era necesario crear una facultad de producir universales, de elevarlos al rango de lo absoluto, de violar los principios que de ellos derivaban y, finalmente, de elaborar las justificaciones teóricas de todas esas violaciones. Es decir una especie de humanismo abstracto que, en palabras de Joaquín Herrera Flores (2006) funcionaba de la siguiente manera: primero, occidente (o su proceso modernizador) se apropia del proceso de humanización que en todo espacio cultural se ha dado y se ha intentado plasmar política, social y normativamente; segundo, ante la necesidad de ocultar tal apropiación 
ilegítima, eleva sus principios a la categoría de absolutos y abstractos, es decir, los "abstrae" de los contextos interactivos en los que han surgido; $y$, tercero, establece una distancia inabarcable entre el discurso proteccionista y las prácticas deshumanizadoras funcionales a sus intereses hegemónicos y geoestratégicos.

Con estos precedentes, sustentaremos una problemática arraigada desde hace más de 500 años: La situación desventajosa del indígena amazónico y los matices negativos que su identidad, construida por otros o desde afuera, arrastra y adopta. Cabe acotar que en este trabajo se evitará la elaboración de inventarios donde se detallen abusos, atrocidades y/o reportes sobre despojos, violaciones o masacres. Lo que se pretende es el planteamiento de una crítica más sutil y, desde un punto de vista cultural y ontológico, algo más significativo. Un cuestionamiento sobre los silenciamientos y asimilaciones llevados a cabo no por militares, policías o mercenarios, sino por intelectuales, religiosos o por algunos defensores de los derechos humanos en el marco de campañas o cruzadas de carácter humanitario cuyo propósito era el de frenar la esclavitud y el genocidio; y, aunque a través de estas prácticas salvaron algunas vidas y conmocionaron a la opinión internacional, nunca tomaron en cuenta las expectativas, visión y creencias de ese "otro" tenido siempre como sujeto subalterno.

Situándonos geográficamente en la cuenca del río Amazonas apreciamos, a primera vista, la gran extensión de la misma y cómo ésta surca el territorio de nueve países. Sin embargo, contrariamente a lo dicho por Euclides da Cunha (PIZARRO, 2012), es importante recordar que tales territorios jamás se encontraron vacíos. La naturaleza pródiga e impetuosa que allí arraiga desde hace siglos, convive con un número importante de etnias nativas que supo interactuar con tales recursos sin necesidad de depredar el medio o ser artífices de feroces genocidios. No obstante, conforme se invadía y ocupaba ese territorio los recursos naturales comenzaron a explotarse de manera desmedida. Para ello, era necesario "borrar del mapa" a quienes interferían con los planes "desarrollistas" de los gobiernos nacionales y de las grandes corporaciones multinacionales. Por ende, además de aplicarse y legitimarse un aparato represor sin precedentes, en el plano cultural, se intentó desterrar toda manifestación 
vinculada a las estructuras míticas de las cosmogonías indianas. Era menester, por tanto: “... trazer a civilização a um lugar tão selvagem” (PIZARRO, 2012, p. 129). En esa dirección, los gobiernos debían:

"colonizar sob o argumento do Estado-Nação". Esto trajo consigo, en la arena del discurso, la colisión y superposición de tres voces: la de los coroneles de la borracha o barones del caucho, portadores de un poder que intentan justificar y legitimar; la de los intelectuales que se plasma a través de textos escritos como documentales, obras literarias, ensayos, periódicos, etc.; y, por último, las voces reconstruidas de las víctimas, difundidas por lo general de modo indirecto: peones indios o mestizos (PIZARRO, 2012, p. 129).

Ante semejantes atropellos, surgieron personajes que intentaron frenar la explotación y la aniquilación de los pueblos sometidos (y no sólo en la Amazonía) a través de actos concretos. En este orden de ideas, se puede rescatar la labor precursora de Fray Bartolomé de las Casas a favor de los indígenas mexicanos, durante los primeros años de la colonización española en tierras aztecas. Empero, debe remarcarse que la praxis humanitaria de Las Casas fue parte de un discurso mayor: el catequista, a partir del cual se daba protección al indígena bajo la condición de borrar sus raíces espirituales-culturales. En consecuencia, estos debían asumir la cultura y ciencia hegemónicas, aceptar el statu quo impuesto por las metrópolis y aceptar al dios de los cristianos.

Como el proceso de conquista no se restringe a los primeros años del encuentro intercultural (siglos XV-XVI), puede decirse que la ocupación de los territorios americanos fue progresiva y que se extiende hasta nuestros días. Para tal efecto, ambos modus operandi invasivos, es decir el del asesinato y el del silenciamiento, se siguen utilizando. Como una forma de documentar esta aseveración, haremos referencia de lo ocurrido, a comienzos del siglo XX, en las riberas de los ríos Putumayo y Caquetá, en la zona denominada "Alto Putumayo", zona, por aquellos días en litigio y sobre la que el Estado peruano ejercía una débil presencia. Poco después y en virtud del tratado de límites Salomón-Lozano firmado en 1922, dicha región pasaría a formar parte de Colombia.

Debido a esa casi nula presencia del Estado y a la progresiva llegada de caucheros peruanos, colombianos y brasileros, las etnias indígenas de la región (huitotos, andoques, boras, etc.) fueron esclavizadas y sometidas a 
una larga lista de vejámenes. Ante esta situación, tuvo que difundirse, más allá de los límites físicos de la región amazónica, dos textos fundamentales donde se daba testimonio de los horrores antes mencionados. Uno de ellos es el libro The devil's paradise cuyo autor es el ingeniero norteamericano Walter Harderburg. En él, si bien se toma partida por la situación de desamparo y peligro permanente de los indios del lugar, ésta es presentada desde una perspectiva proteccionista, es decir, como menores que precisan del cuidado o educación de humanos "más evolucionados". Sobre esto el autor referido señala:

Os pobres índios, apesar da 'civilização' diabólica dos peruanos, nunca foram ensinados a ler ou escrever, não têm amigos para protegê-los e, não obstante seus treze anos de contato com essa "empresa civilizadora" de Arana, nunca ouviram falar da existência de Deus, e suas mentes estão cauterizadas e entorpecidas pelos longos anos de atrocidades nas mãos desses monstros. os índios são pagãos, mas são humanos, assim como nós somos; eles têm almas; têm afeiçoes e amor e valorizam seus entes queridos, tal como amamos os nossos; eles são nossos irmãos. E se eles são pagãos, selvagens e ignorantes, de que é a culpa? É culpa desses demônios, que durante anos se aproveitaram de sua ignorância e impotência, explorando sua mansidão e humildade, e aprisionando-lhes em cadeias de ferro da escravidão chocante em que estão agora detidos. E quando vemos que são ignorantes e impotentes e não podem protestar contra seu terrível destino, não é o nosso dever, por isso mesmo, defendê-los da forma mais enérgica? (HARDERBURG, 2016, p.135).

Luego de leer el párrafo anterior, vale preguntar: hasta qué punto, esos humanos caídos en desgracia, se pueden asemejar a esos otros humanos portadores de la "cultura y del progreso occidental"? Deben, acaso, abandonar lo suyo o sea aquello que los torna distintos y a la vez vulnerables? Aunque la posición humanitaria de este ingeniero norteamericano sentó un precedente en la lucha por la abolición de la esclavitud, su discurso se ve salpicado de pequeñas fórmulas retóricas cuyo sentido incluye una inocultable intención colonizadora. El indio, en estas instancias, es un sujeto humano, más, un humano hecho a imagen y semejanza del hombre blanco? Indudablemente, la humanidad del sujeto expoliado no es puesta en duda, sin embargo, su estadio ético-cognitivo no es el de un adulto. El indio, para Harderburg, es una criatura que, para salvarse y vivir, debe abrazar la civilización occidental. En otras palabras, 
optar por una "adultez" que se traduciría en la pérdida de su cultura, de su religiosidad, idioma, etc., en aras de una cultura que avanza y no repara en quienes, aferrados a sus raíces, se resisten a toda "contaminación" o aculturación.

De este modo, se devela una faceta de la operación silenciadora que, investida de acto altruista, disminuye y hasta anula la cultura del indio, quedando la paradoja, en tanto, de su necesaria implementación pues ello sería preferible a los efectos de la muerte, el estupro, de la tortura. No obstante, cabría preguntarse se esta muerte simbólica o silenciamiento sería tan o más perniciosa que los efectos inmediatos del genocidio?

Un hecho llamativo es que uno de los principales sectores preocupados en proteger a los indios sea el religioso. De manera sutil (y también violenta) ven en la catequización de los indígenas una misión necesaria e impostergable, lo que se traduce, desde años atrás, en la implementación de misiones (católicas o protestantes). La religión del indio, para ellos y para la ideología dominadora, es un conjunto de prácticas paganas, aberrantes y bárbaras que deben extirparse. ${ }^{2}$

Llama la atención, pues, la arenga que Harderburg profiere al final del capítulo 5 del libro antes citado: "Povo de Inglaterra! Pessoas justas e generosas, sempre as sentinelas avançadas do cristianismo e da civilização! Levai em consideração esses horrores! Ponham-se no lugar das vítimas, e libertem esses poucos índios remanescentes da escravidão cruel e exijam punição aos autores dos crimes!” (HARDERBURG, 2016, p. 144). Si tenemos en cuenta que Inglaterra es una nación de larga trayectoria imperial, nutrida de la riqueza de pueblos ocupados y devastados e involucrada, además, en más de una guerra de proyecciones nefastas, puede tomarse en serio la arenga de Harderburg?

El otro texto escrito con la intención de denunciar los crímenes del Alto Putumayo es El libro Azul de Roger Casement. Tales crímenes fueron cometidos, principalmente, por los empleados de la Peruvian Amazon Company, empresa dedicada a la explotación del caucho, cuyo dueño era el peruano Julio César Arana y cuya sede corporativa se ubicaba

2 Esto, lejos de suprimir definitivamente la espiritualidad indígena ocasionó formas de resistencia o asimilación parcial como el sincretismo religioso y cultural. 
en Londres. Por encontrarse en Inglaterra, la Corona británica envía a uno de sus diplomáticos (Casement) a investigar lo también denunciado por Harderburg y el periodista peruano Benjamín Saldaña Roca. Como resultado aparece un libro revelador compuesto principalmente por cartas, telegramas y testimonios, que, en un primer momento y por pedido expreso del Gobierno peruano, no fue publicado ni difundido; mas, debido a la intransigencia institucional peruana y ante las presiones de Arana, jamás se aplicó sanción definitiva a los responsables de los actos denunciados. Por tal razón, el informe de Casement vio la luz, tiempo después, con el nombre de El Libro Azul.

Pese a la preocupación humanitaria y la labor titánica de Casement, la visión que este diplomático tenía no era muy distinta a la de Harderburg. Como la del ingeniero norteamericano, la óptica de aquél deja entrever que la única civilización viable, destinada a pervivir por siempre sin que ninguna otra le haga frente o se desarrolle simultáneamente, es la del hombre blanco, pero, la del hombre blanco anglosajón, de la Europa (o América) occidental y no la del hombre blanco latino-americano. En este contexto, si bien el indio era visto como un niño, el puñado de blancos y mestizos peruanos y en menor cuantía colombianos y brasileros (aunque muchas veces con justa razón) eran categorizados, también, como bárbaros y como portadores de una civilización fallida, a todas luces inferior a las de Gran Bretaña o Estados Unidos.

El propósito de los intrusos "civilizados" no era, en primera instancia, aniquilar a los indios sino "conquistarlos", es decir, subyugarlos y ponerlos a trabajar en una ocupación considerada civilizada y, en todo caso, provechosa para ellos. Esos subyugadores se organizaron en bandas y partidas, asociaciones comerciales agrupadas, y después de sobreponerse a la resistencia de los indios, se apropiaron de ellos para su uso exclusivo junto con los árboles de caucho que se encontraban en la región que habitaban. A partir de ese momento, para el jefe de la banda se convirtieron en "mis indios" y cualquier intento hecho por uno de sus vecinos civilizados para robar, engatusar o enrolar a sus indios se volvió una ofensa capital. Así, donde el primitivo salvaje redaba a su vecino salvaje por razones que le parecían buenas, el hombre blanco que vino en una supuesta misión de civilización para acabar con el salvajismo primitivo redaba, a su vez, a su semejante blanco por razones que al indio le parecían totalmente equivocadas, puesto que acarreaban su segura esclavitud. Los constantes robos de indios de un "cauchero" a otro condujeron a represalias más sangrientas y 


\section{ARTIGO}

asesinas que cualquier cosa que los indios jamás hubieran podido hacer contra otro indio... (CASEMENT, 2011, pp. 49-50).

El indio era, pues, un menor de edad, un "discapacitado mental" portador de una candidez original que lo convertía en el "blanco perfecto" de las ambiciones de los caucheros. Ante ello, era deber de la "verdadera civilización” protegerlo y rescatarlo. Empero, tal protección implicaba asimilarlo e incorporarlo a un mundo que siempre le fuera esquivo.

Al principio, el indio, quien más correctamente debería ser llamado "un niño crecido", estaba feliz de tener un hombre blanco asentado en la vecindad con artículos atractivos que ofrecer; y traer caucho para ser intercambiado por estas tentadoras bagatelas parecía cosa fácil. Además, el indio es por naturaleza dócil y obediente. Su debilidad de carácter y docilidad de temperamento no tienen como encarar la habilidad de dominación de las personas con sangre europea en las venas (CASEMENT, 2011, p. 51).

La supuesta "superioridad" étnico-cultural, aunque no se exprese de manera directa y abierta, es un tópico que se percibe a lo largo del texto. Por otro lado, tanto el narrador como sus interlocutores (funcionarios de la Corona británica y capataces barbadenses) junto a autores de misivas, informes y otros documentos, develan en su discurso marcas donde la impronta colonial es incuestionable. Estas pueden verse, además, en el discurso catequista de los misioneros católicos que, en contacto con Casement, muestran una actitud similar a la de los antiguos caballeros cruzados que debían convertir (y asimilar a occidente) a los "infieles" de oriente. Testimonio de ello da el siguiente informe de Frei Prat:

Año 1903 - En el mes de abril de este año, una misión fue designada por el Reverendo Padre Prefecto en Pebas, en la margen izquierda del Ampiyacu, un afluente del Marañón. Los Rev. Padres Pedro Prat y Plácido Mallo fueron nombrados para esta misión y buscaron por todos los medios convertir a los infieles 'yaguas', algunos de los cuales habitan en la vecindad de Pebas, aunque la mayor parte vive en localidades más distantes, obteniendo, sin embargo, magros resultados debido al 'poquísimo apoyo' de los 'caucheros' ('explotadores de goma elástica'), quienes tienen interés que los salvajes permanezcan 'en la más crasa ignorancia' para poder explotarlos con mayor facilidad.

(...) El revendo hermano continúa contando cómo el prefecto apostólico visitó a esos indios yaguas a pie, atravesando dificultades y privaciones para alcanzar a 'esos desdichados infieles', y cómo después de tanta labor el 
misionario encontró la oposición de los 'caucheros', quienes querían evitar que él aprendiese a hablar la lengua de los yaguas. (CASEMENT, 2011, pp. 81-82).

Como se observa, resaltan en el fragmento epítetos como los de infiel, salvaje y desdichado. El indio es, para esos religiosos, portador de una cultura que debe desechar. Para ello, necesita abrasar la doctrina cristiana y, amansado y disciplinado, convertirse en un ciudadano remoto, de inferior categoría, pero ciudadano a final de cuentas.

Nos encontramos, sin lugar a duda, ante narrativas que, aunque promuevan la preservación del indígena, pugnan, por otro lado, para que éste renuncie a su cultura. Entonces, cabe preguntar si la violencia simbólica ejercida y disfrazada de humanitarismo, donde la vOz del otro se halla menoscabada o al margen de la historia, acarrea las mismas consecuencias que la violencia física y terror practicados por la compañía de Julio César Arana.

Basándose en los escritos de Harderburg y Casement, Mario Vargas Llosa redacta, casi 100 años después, El sueño del celta (2010), una biografía literaria de Roger Casement en la cual se enfatiza su paso por el Congo belga y la Amazonía peruano-colombiana, en tiempos de la denominada fiebre del caucho. A través de este libro es posible ver cómo la literatura se nutre de la historia y cómo la historia puede enunciarse a partir de la literatura, generándose, así, puntos de contacto o intersecciones donde realidad e invención entrelazan sus aristas; un territorio especial, autónomo, denominado ficción.

Desde este discurso ficcional, el autor modela la materia histórica y se introduce, igualmente, en el terreno de la etnología, de la ética y de la investigación periodística. De este modo, crea un documento cuya narrativa ágil y bien construida nos sumerge en el infierno de los explotados y en el drama que le tocó vivir a Roger Casement como sujeto colonizador (funcionario de la Corona británica) y colonizado (irlandés independentista).

Desde su arribo a Iquitos (Perú), el narrador observa cómo los espacios que circundan al irlandés se pueblan de situaciones chocantes. El tema de la dominación "solapada y silenciosa", por otro lado, aparece en 
el discurso de los personajes "civilizadores" que desde la ciudad-puerto de Iquitos buscan diferenciarse de las "fieras" que explotan el caucho en el Alto Putumayo. Tal es el caso del cónsul británico de aquél enclave peruano quien, en torno al problema de la venta de niños indígenas en poblados peruanos y brasileros, refiere:

Por lo demás, no se haga ilusiones. Usted no va a cambiar lo que ocurre aquí, señor Casement. Y el padre Urrutia tampoco. En cierto sentido, para estos niños es una suerte lo que les ocurre. Ser sirvientes, quiero decir. Sería mil veces peor que crecieran en las tribus, comiéndose los piojos, muriendo de tercianas y cualquier peste antes de cumplir diez años, o trabajando como animales en las caucherías. Aquí viven mejor. Ya sé que este pragmatismo mío le chocará (LLOSA, 2010, p.122).

Puede decirse que la confrontación entre las dos posturas colonizadoras: la violenta y la sutil, llega a su clímax en la cubierta del barco Huayna. Tal episodio tiene como protagonistas a Roger Casement y al aviador judío Víctor Israel. El problema del indio, de la explotación del caucho y de la destrucción de su hábitat es un asunto que se debe solucionar sólo desde esas dos perspectivas, es decir, sin jamás considerar las perspectivas de los propios sujetos sometidos.

- Me gustaría saber cuál es su idea de la civilización - dijo Víctor Israel. (...)

- Se podría sintetizar diciendo que es la de una sociedad donde se respeta la propiedad privada y la libertad individual - explicó, con mucha calma, todos sus sentidos alertas por si Víctor Israel intentaba agredirlo -. Por ejemplo, las leyes británicas prohíben a los colonos ocupar las tierras de los indígenas en las colonias. Y prohíben también, con pena de cárcel, emplear la fuerza contra los nativos que se niegan a trabajar en las minas o en los campos. Usted no piensa que la civilización sea eso. ¿O me equivoco? (...)

- Según ese criterio - afirmó, burlón e hiriente -, los peruanos tendrían que dejar que la Amazonía continuara en la Edad de Piedra por los siglos de los siglos. Para no ofender a los paganos ni ocupar esas tierras con las que no saben qué hacer porque son perezosos y no quieren trabajar. Desperdiciar una riqueza que podría levantar el nivel de vida de los peruanos y hacer del Perú un país moderno. ¿Eso es lo que propone la Corona británica para este país, señor Casement?

- La Amazonia es un gran emporio de riquezas, sin duda - asintió Casement, sin alterarse - . Nada más justo que el Perú las aproveche. Pero sin abusar de los nativos, sin cazarlos como animales y sin trabajo esclavo. Más bien, incorporándolos a la civilización mediante escuelas, hospitales, iglesias. Víctor 
Israel se echó a reír, estremeciéndose como un muñeco de resortes (LLOSA, 2010, p. 124).

Como una manera de ilustrar las consecuencias del contacto forzado entre sujetos de culturas disímiles y, siguiendo siempre la perspectiva etnocéntrica del personaje Casement, citaremos el caso de los niños indígenas, rescatados por el irlandés y llevados a Inglaterra. El contacto entre un mundo y otro resulta poco saludable y los efectos de la sobreexposición genera en los menos fuertes una sensación de malestar que les impide continuar en Europa y convertirse, por siempre, en material exótico de exhibición, en un "otro" siempre extraño, maculado y marcadamente distinto.

Pero Roger se encontró con dos chiquillos a los que la civilización, pese a darles de comer, no golpearlos ni flagelarlos, los había entristecido y apagado. Parecían siempre temerosos de que las gentes que los rodeaban, sometiéndolos a un escrutinio inagotable, mirándolos de arriba abajo, tocándolos, pasándoles la mano por la piel como si los creyeran sucios, interrogándolos con preguntas que no entendían y no sabían cómo responder, fueran a hacerles daño. (...) Todos los trataban con cariño pero la curiosidad con que eran examinados, sobre todo cuando tenían que sacarse las camisas y enseñar las cicatrices en las espaldas y en las nalgas, los turbaba. A veces, Roger descubría los ojos de los chiquillos cuajados de lágrimas. (...) cuando recibió la respuesta de Pearse, Roger ya había decidido consentir a lo que Omarino y Arédomi le rogaban a diario: regresarlos a la Amazonia. Ambos eran profundamente desdichados en esa Inglaterra donde se sentían convertidos en anomalías humanas, objetos de exhibición que sorprendían, divertían, conmovían y a veces asustaban a unas personas que nunca los tratarían como iguales, siempre como forasteros exóticos. (...) Y, sin embargo, aquí, aunque por razones distintas, estaban tan lejos de la felicidad o, por lo menos, de una existencia tolerable, como en el Putumayo. Aunque no les pegaran y más bien los acariñaran, se sentían ajenos, solos y conscientes de que nunca formarían parte de este mundo (LLOSA, 2010, pp. 174-175).

Por otro lado, la adscripción cultural del narrador heterodiegético que le da voz y movimiento a la figura de Roger Casement, es prácticamente la de dicho personaje pues, en ningún momento, cuando se habla de su labor y de sus reflexiones proteccionistas, se generan conflictos o críticas de algún tipo. Esta voz narradora remarca, en más de un punto, la disparidad existente entre la civilización occidental y la "barbarie amazónica". Dos mundos distintos que jamás podrían consustanciarse, mas sí superponerse, 
teniendo que ser la occidental, la cultura que estuviese siempre por encima. Esto se aprecia en el pasaje donde el narrador establece un paralelo entre el paisaje amazónico y la campiña irlandesa:

No podía haber nada más distinto del amable y civilizado paisaje de Cornwall que el de la Amazonia y, sin embargo, pese al bienestar y la serenidad que sentía aquí, viendo la rutina de los granjeros, pastar a las beatíficas vacas y relinchar a los caballos de los establos, sin amenazas de fieras, serpientes ni mosquitos, se encontró un día pensando que esta naturaleza, que delataba siglos de trabajo agrícola al servicio del hombre, poblada y civilizada, ya había perdido su condición de mundo natural - su alma, dirían los panteístas - comparada con aquel territorio salvaje, efervescente, indómito, sin amansar, de la Amazonia, donde todo parecía estar naciendo y muriendo, mundo inestable, riesgoso, movedizo, en el que un hombre se sentía arrancado del presente y arrojado hacia el pasado más remoto, en comunicación con los ancestros, de regreso a la aurora del acontecer humano. Y, sorprendido, descubrió que recordaba aquello con nostalgia, a pesar de los horrores que escondía (LLOSA, 2010, p. 192).

De tal forma, se aprecia en esta narrativa los alcances de un sistema ideológico destinado a opacar toda diferencia o atisbo de "barbarie". Aunque se repudia la brutalidad de los caucheros y en más de una ocasión se los rotula como los verdaderos incivilizados, la cultura indígena no deja de mostrarse como un estorbo, como una rémora que impide el desarrollo de las naciones y que por ello debe desnaturalizarse o desaparecer. Empero, así como las etnias indígenas deben ser parte de un Estadonación que no respeta la diversidad y el estatuto humano y espiritual del "otro", las naciones latinoamericanas deben, igualmente, ser parte de un sistema mayor regido desde los centros metropolitanos mundiales. Y tal como ocurre con las comunidades indígenas, la nación no hegemónica que intente seguir su propio camino sería tildada de bárbara, inviable y condenada al fracaso.

En este sentido, vale hablar un poco del mismo Mario Vargas Llosa y su postura conservadora actual. Este intelectual peruano es un portavoz activo de la modernidad occidental, del cosmopolitismo y de las libertades económicas que mueven a las sociedades capitalistas; sin embargo, tal postura, precisamente, es la de un sector de la sociedad y de la intelectualidad peruana que, a la luz del fenómeno de la heterogeneidad, 
se desarrolla bajo las directrices de occidente. Esto se puede revelar en el siguiente parlamento desarrollado a lo largo de una conversación entablada con Arcadio Díaz Quiñones y Tomás Eloy Martínez.

La modernidad sólo es ya problemática para los que ya son modernos. Porque, si eres moderno puedes darte el lujo de desacreditar y reivindicar, en cambio, lo primitivo, lo arcaico. Pero vista desde la perspectiva de un peruano, de un paraguayo, de un somalí, la modernidad es un problema de vida o muerte para inmensas masas que viven en el primitivismo no como si fuese un juego intelectual de antropólogos y politólogos, sino como gente desamparada ante un mundo cada vez más hostil. Si eres un político y tienes un mínimo de responsabilidad no puedes plantear la modernidad como un debate académico. En el Perú la modernidad es trabajo para los que no trabajan, instrucción básica para los que no tienen instrucción, y un mínimo de oportunidades para que gentes condenadas a la marginalidad desde su nacimiento puedan ganarse la vida (PÁGINA 12, 1993).

Como se observa, la actitud y visión de Vargas Llosa es muy similar a la del Roger Casement literario, situación que, asimismo, no está exenta de más de un conflicto. Este conflicto se expone con mayor fuerza en la novela El hablador, donde la voz modernizadora, adrede, entra en colisión, en la diégesis misma, con la de los intelectuales defensores de las comunidades amazónicas. Saúl Zuratas, alias Mascarita, protagonista de la novela El hablador, ante las propuestas y políticas de asimilación, dirigirá sus críticas a todo una multitud de funcionarios nacionales y extranjeros, lingüistas y religiosos cuyo objetivo principal fue siempre el de borrar todo rastro de las culturas amazónicas. Para Zuratas, la labor de los evangelizadores protestantes norteamericanos es aún más perniciosa que la de políticos, empresarios o militares. Gracias a su poder económico, estos extranjeros lograron desplazar a los sacerdotes católicos de las misiones selváticas, manipular a las mismas autoridades regionales y nacionales e iniciar, así, un proceso irreversible de aniquilación de la espiritualidad, lenguas y culturas e nativas amazónicas. Según este defensor de la causa indígena:

- Ellos son los peores de todos, tus apostólicos lingüistas. Se incrustan en las tribus para destruirlas desde adentro, igualito que los piques. En su espíritu, en sus creencias, en su subconsciencia, en las raíces de su modo de ser. Los otros les quitan el espacio vital y los explotan o los empujan más adentro. En el peor de los casos, los matan físicamente. Tus lingüistas son más refinados, los quieren matar de otro modo. ¡Traduciendo la Biblia al machiguenga, qué 
te parece! (...) Ellos también les quieren robar el alma, por supuesto. Pero, a los misioneros se los está tragando la selva, como al Arturo Cova de La vorágine. ¿No los has visto, en tu viaje? Medio muertos de hambre y, además, poquísimos. Viven en un desamparo tal que ya no están en condiciones de evangelizar a nadie, felizmente (...) Los lingüistas eran algo muy diferente. Tenían, detrás de ellos, un poder económico y una maquinaria eficientísima que les permitiría tal vez implantar su progreso, su religión, sus valores, su cultura. ¡Aprender las lenguas aborígenes, vaya estafa! ¿Para qué? ¿Para hacer de los indios amazónicos buenos occidentales, buenos hombres modernos, buenos capitalistas, buenos cristianos reformados? Ni siquiera eso. Sólo para borrar del mapa sus culturas, sus dioses, sus instituciones y adulterarles hasta sus sueños. Como habían hecho con los pieles rojas y los otros, allá en su país. ¿Eso quería para nuestros compatriotas de la selva? ¿Que se convirtieran en lo que eran, ahora, los aborígenes de Norteamérica? ¿Que se volvieran sirvientes y lustrabotas de los viracochas? (LLOSA, 1995, pp. 37-39).

Como se observa, la óptica occidental es incapaz de captar la otredad en su verdadera dimensión; por tal motivo, empequeñece, reduce y hasta extermina todo aquello que difiera de sus patrones culturales. Entonces, quién es el verdadero ignorante? Aquél que desarrolla prácticas bárbaras (dígase genocidas)?, aquél que desestabiliza, que arrasa? O aquél que mira el mundo desde otra lente y trata de preservarlo?

Mucha sangre corrió y sigue corriendo en ese vasto territorio denominado Amazonía. Tal situación, lamentablemente, no se restringe a un solo país sino que se da a lo largo y ancho de esa zona natural como tal ocurrió en el Alto Putumayo a inicios del siglo XX. La existencia de políticas arbitrarias, unilaterales; la injerencia de intereses económicos multinacionales; el discurso progresista de algunos intelectuales y la labor proteccionista de ciertos filántropos, constituyen, aún hoy, detonantes que tornan dicha problemática en una herida expuesta o no cerrada. A la explotación del caucho o de la madera, se suceden otras actividades extractivas primarias -no menos perniciosas- como la explotación del oro, del petróleo, de gas natural, etc. Éstas, invaden, ocupan y toman posesión de los territorios de las comunidades, sin mediar, en la mayoría de casos, negociación alguna.

En consecuencia, los conflictos generados en ese amplio territorio no son pocos. Sin embargo, estos son ocultados o distorsionados por los medios de comunicación al servicio del gran capital. Puede ser que 
algunos pueblos hayan hecho respetar sus derechos, mas el balance global no es nada alentador. El discurso del progreso avanza y sus plataformas de difusión y afianzamiento expanden cada vez más su espectro. Ante ello, queda todavía el terreno intelectual, académico y, aunque la lucha llevada a cabo en estas "arenas" sea desgastante y los logros obtenidos escuetos, que las pequeñas satisfacciones sean un aliciente e impulsen la utopía.

\section{Referencias}

CASEMENT, R. El Libro Azul. Informes de Roger Casement y otras cartas sobre las atrocidades en el Putumayo. Traducción al español de Luisa Elvira Belaunde. Lima. Centro Amazónico de Antrapología y Aplicación Práctica. 2011. Disponible en: $<$ https://goo.gl/E1DQrG> Accedido el 20 de julio de 2016.

FLORES, J.H. "Colonialismo y violencia. Bases para una reflexión pos-colonial desde los derechos humanos". Revista Crítica de Ciências Sociais. Universidade de Coímbra, Portugal. Outubro de 2006. Disponible en: <https://goo.gl/ bzZbfj> Accedido el 10 de octubre de 2017

HARDENBURG, W. O paraíso do diabo. Relato de Viagem e Testemunho das Atrocidades do Colonialismo na Amazônia. Tradução de Hélio Rocha. São Carlos-S.P. Editora Scienza. 2016.

HISTORIA DEL PERÚ. “Fiebre del caucho”. Disponible en: < https://goo.gl/ ibyNqw> Accedido el 10 de agosto de 2016.

LLOSA, M. V. El Hablador. Barcelona. Seix Barral. 1995. Disponible en: $<$ https://goo.gl/Af9cbn> Accedido el 23 de julio de 2016.

LLOSA, M. V. El sueño del celta. Madrid. Santillana Ediciones Generales. 2010. Disponible en: <https://goo.gl/yYzM7e> Accedido el 25 de julio de 2016.

PÁGINA 12. "La modernidad a cualquier precio". Conversación con Mario Vargas Llosa, Arcadio Díaz Quiñones y Tomás Eloy Martínez. Buenos Aires, 9 de mayo de 1993. Disponible en: < https://goo.gl/jRbkYF> Accedido el 05 de agosto de 2016.

PIZARRO, A. Amazônia: as vozes do rio. Tradução Rómulo Monte Alto. Belo Horizonte. Editora UFMG. 2012.

Data de recebimento: 29/10/2018

Data de aceite: 28/12/2018 